\title{
A Case Study on the Adoption of Cloud Computing in Malaysia from The Perspectives of Cloud Providers
}

\author{
Noor Hazwani Mohamad Puad ${ }^{1}$, Asma Md $\mathrm{Ali}^{2}$, Mohd Adam Suhaimi ${ }^{3}$, and Husnayati Hussin ${ }^{4}$ \\ 1,2,3,4 Universiti Islam Antarabangsa Malaysia, Malaysia \\ hazwanipuad@gmail.com ${ }^{1}$, sisasma@iium.edu.my ${ }^{2}$, adam@iium.edu.my ${ }^{3}$, husnayati@iium.edu.my ${ }^{4}$
}

Corresponding author: husnayati@iium.edu.my

Received: 15 September 2018, Accepted: 16 January 2019, Published: 13 July 2019

\begin{abstract}
The objective of this study is to discover the perspectives of cloud providers towards cloud computing adoption in Malaysia in terms of the challenges faced by cloud providers and reasons for the adoption. Data were collected through semi structured interviews with three cloud providers. The findings indicated security concern, difficulties in learning cloud computing infrastructure, changes in IT roles, high cost of bandwidth and life span of IT equipment as challenges faced by cloud providers in providing cloud service in Malaysia. This study also discovered cloud scalability, end-to-end management, high level security, and customizable as the reasons on cloud computing adoption. The findings of this study help people to understand more about the current situation of cloud computing adoption in Malaysia.
\end{abstract}

Keywords-cloud adoption, cloud computing, cloud providers, Malaysia.

\section{I.INTRODUCTION}

Cloud computing is one the promising technology for the future information technology (IT) field and considered to be the latest revolution of the internet [1], [2]. Over the years, the number of interests has increase in its implementation due to its ubiquitous characteristics [3]. Even, cloud computing has been considered as an essential utility like other important utilities such as electricity, water, and telephone [4]. Asia Cloud Computing Association (ACCA) Readiness Index 2018 evaluates 14 Asian countries and ranked Malaysia as 8 th position. This indicates the fact that cloud computing adoption among Malaysia companies and organizations require improvements.

With all the claimed benefits for organizations that implement cloud computing including reliability, flexibility, scalability and cost savings [5], [6], [7], [8] there are also concerns over the potential risks of implementing cloud computing. Scant attention is given to the issue of privacy and security as many researchers has stated privacy and security issues as one of the biggest reasons for a company or organization not to implement cloud computing [3], [9], [10].

Cloud computing providers are those companies that offer network services, infrastructure or business application in the 'cloud' where it will be hosted in the data center. The role of providers is very crucial in the case of cloud computing services. The objective of this study is to understand the challenges faced by cloud providers in providing cloud services to companies and organizations in Malaysia. This study aims to help cloud service providers and consumers to understand more about current situation of cloud computing adoption in Malaysia and facilitate toward the progress of the Industry 4.0 [11].

\section{LITERATURE REVIEW}

Talking about the definition of cloud computing, the most common and well-known is the definition stated by America National Institute of Standards and Technology (NIST). NIST defined cloud computing as "a model for enabling convenient, on demand network access to a shared pool of configurable computing resources (e.g., networks, servers, storage, applications, and services) that can be rapidly provisioned and released with minimal management effort or service supplier interaction" [12]. According to [13] cloud computing representing two major keys in information technology (IT), which is IT efficiency and business agility. In terms of IT efficiency, cloud computing allows modern computer to utilize efficiently and it also enhance IT to be used in mobile interactive applications that responds in real time user requirement. Business agility on the other hand represents the effective and strategic use of IT tools by businesses to gain competitive edge through for example rapid and scalable deployment, cost efficient procurement and avoiding huge upfront payment for ICT infrastructures.

Asia Cloud Computing Association in Cloud Readiness Index 2018 evaluates 14 countries in Asia including Malaysia in terms of cloud computing adoption where Malaysia ranked 8th place. There are 10 indicators measured in the evaluation: International connectivity, broadband quality, power and sustainability, cybersecurity, privacy, government regulatory environment, IP protection, business sophistication, and freedom of information. It has been stated in the report [14] that Malaysia performed well 
in the Cybersecurity parameter at the same time made moderate progress in Government Regulatory Environment compared to last year. In order to improve the adoption of cloud computing in Malaysia, [14] recommended Malaysia to focus on improving its cloud infrastructure especially in terms of broadband speed. Other than that, it is advisable for Malaysia to review its freedom of information and privacy laws as current laws seems to go against the dynamism that cloud computing can bring about. Plus, it is necessary for Malaysia to improve its regulatory environment by demonstrating the value of cloud technologies to help businesses and government agencies.

Over the past years, many researches related to cloud computing adoption in Malaysia have been conducted. Most of the related researches aim to understand the adoption of cloud computing in Malaysia from the perspective of clients [15], [16], [17], [18]. Three of the papers mentioned above applied the Technology Organization Environment (TOE) framework to identify the determinants factors affecting the adoption of cloud computing [14], [15], [18]. [15] in their study identified cost saving, top management support, competitive pressure, and trading partner pressure give positive impacts on cloud adoption while security and reliability issues as negative factors of cloud adoption in Malaysia. On the other hand, [17] focused on identifying the organizational factors affecting the adoption of cloud computing where the researcher discovered only information technology (IT) resources affect cloud adoption while there is no significant relation between top management support and employee knowledge on cloud computing adoption. [18] in their study found cost saving, top management support and technology readiness as the factors affecting cloud adoption among SMEs in Sabah. However, they did not find any significant relation between relative advantage, competitive pressure, and external support on cloud adoption.

Meanwhile, [19] chose accounting practitioners both in the audit and commercial fields as their samples where they discovered, cost and time saving as the main reasons for cloud adoption, while lack of perceived benefits, and security as the reasons for nonadoption. [20] and [16] used Diffusion of Innovation (DOI) theory in their studies to identify factors affecting cloud adoption among organization in Malaysia. [20] found significant relation between relative advantage, compatibility and IT personnel knowledge on cloud adoption. While [16] found only complexity influenced the cloud computing adoption.

However, research that is related to the cloud computing adoption from the providers' perspectives is hard to find. The only literature that the researcher found which is the most related with this study is conducted by [21] where their study aims to discover the determinants of clients and provider's relationship continuance model. The fact that there are minimal studies conducted to understand more about cloud computing adoption especially in Malaysia from the provider's perspective [22] has motivated the researchers to conduct this study.

\section{METHODOLOGY}

This study is a case study research as the case study method provides a good design method for understanding the adoption of cloud computing in Malaysia from providers' perspectives. The method is appropriate when researchers are forced by circumstances to define research topics broadly. Typically, case study research is used in qualitative studies to solve questions such as "how" or "why" and ideal for research involving a limited number of respondents. This study employs interview as a data collection method. A semi-structured interview technique allowed the researchers to adapt questioning to the respondent's understanding of the topic under discussion. Questions were not fixed so that the researchers could probe and clarify responses in relation to the dimensions of the research topic. The interviews ranged in duration from 20 to 30 minutes. All the interviews were digitally recorded and transcribed.

The data from the interviews was analyzed using thematic analysis. In this study, the thematic analysis approach used is data driven where the steps involved in building themes are categorizing, conceptualizing and abstracting. Interview transcripts were repeatedly engaged in the interpretive process. This took the form of reading the interview transcripts and noting all significant content relevant to the perspectives of cloud providers towards cloud computing adoption in Malaysia. These codes were developed into themes as the analysis continues and the researchers also returned to the original audio recordings to check pauses and tone of voices. The purpose of this action was to maintain a close link with the interview data during analytical process.

\section{FINDING AND DISCUSSION}

The overview of three cloud providers and their perspective on cloud computing adoption based on the findings are discussed. These includes challenges in providing cloud computing service in Malaysia and reasons on the adoption of cloud computing by companies and organizations in Malaysia. 


\subsection{Cloud Providers Overview}

Cloud Provider A is a Malaysian company that provide web hosting solutions for companies and individuals that aim to build up their business in their respective industries. At the present time, Cloud Provider A is offering a wide variety of enterprise web hosting services to more than 50,000 customers, both local and overseas. The percentage for year-over-year renewal rate is $90 \%$. The key strength of the company is their products and services where they put a lot of thought into designing complete solutions that can help their customers to do well in their respective industries. They also offer variety of web solutions that fit with clients' requirements and expectations such as dedicated server hosting, migration services, managed services, domain name services, web hosting, email hosting, co-location services and cloud hosting. There are several cloud hosting plans that customer can choose according to their business needs. The latest plan offers by the company is the OpenStack Cloud Hosting Plan where customers are allowed to use and pay the cloud services by per hour or by per month.

Cloud Provider B is a German global IT services and consulting company founded in 2000. The company was the largest German company and one of the largest European IT services company. Cloud Provider B supports corporate customers in the area of infrastructure operations, as well as managing enduser services. Cloud Provider B is a multi-customer operations hub where it provides services for multiple accounts across the industries and countries. Cloud Provider B provides different types of solutions to their customers and cloud services is one of the solutions. There are three different clouds offer by Cloud Provider B which is Software as a Service (SaaS), Platform as s Service (PaaS) and Infrastructure as a Service (IaaS). Each type of cloud services consists of various types of cloud solutions.

Cloud Provider C is an MSC status company that provide customers with information technology solutions covering all major aspects of systems, solutions and services. The Malaysia company of Cloud Provider C was formally established in 1997. There are three types of solutions offers by Cloud Provider $\mathrm{C}$ which is industry solutions, business and technology solutions and infrastructure solutions. Cloud Provider $\mathrm{C}$ also provides a multi-cloud services where they offer six types of cloud services that customers can choose according to their business needs. The six types of cloud services offered are Fujitsu Managed Private Cloud, Fujitsu Cloud Service K5, Cloud Service Azure, VMWare Cloud on AWS, Oracle Cloud Services, and SAP on Microsoft Azure.

\subsection{Challenges in Providing Cloud Computing in Malaysia}

The challenges are security concern, difficulties in learning the cloud computing infrastructure, changes in IT roles, high cost of bandwidth and lifespan of IT equipment (refer Fig. 1).

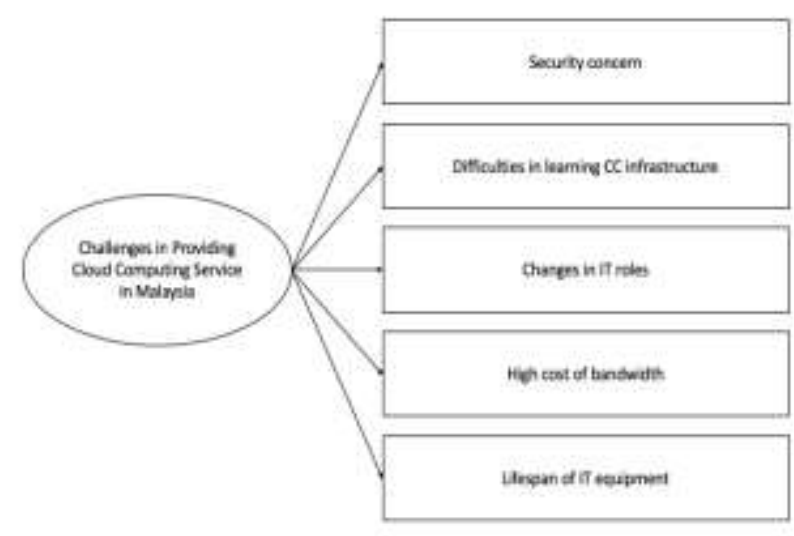

Fig. 1 Mapping nonlinear data to a higher dimensional feature space

This research found that security concern has become the biggest challenge among cloud providers in providing cloud computing in Malaysia. Problems such as data breaches and data losses might have happened when moving from business process to cloud computing. Most of the time, files uploaded to the cloud contain sensitive data of the companies. When a cloud service is breached, cybercriminal can eventually gain access to this sensitive data. This security issue is one of the reasons why people still hesitate to move to the cloud.

"Most of us, most of the entrepreneur, they are very, have a bad feeling in security. They think 'we cannot go to the cloud', 'we cannot share our confidential data'," (Interviewee 3).

"I think, our entrepreneur needs to think our technology nowadays is not like 1990's. We are already moving forward, so we have high security, so entrepreneur no need to worry about this," (Interviewee 3).

"Obviously, security is always a concern of customers that come to cloud computing. In fact, when we present to our customer, we spend half of our time talking about how we manage security and so on," (Interviewee 4).

Difficulties in learning cloud computing structure is another challenge. Although cloud computing has become a phenomenon in the IT field over the last decades, this technology is still at its infancy and slowly being adopted by businesses in Malaysia. This is because, some people are still not familiar with 
cloud infrastructure. Although cloud computing has been said as a technology that is 'simple-to-use', it still has its own complexity. Cloud services have the ability to cover the whole business process, this might take some time for those people who are used to the traditional way. Plus, they still believe, to move to the cloud, they need to have a complete organization structure and only after that they will start thinking about adopting cloud computing in their business.

"As it's a new trend, many people may face difficulty to learn its infrastructure," (Interviewee 1).

Moving to cloud computing means the role of IT experts in organizations will change. Although migrate to the cloud does not eliminate the need for IT supports or departments, they eventually need to adjust their skills according to cloud computing landscape. Their jobs will be less about technology but more about how to optimize technology to make businesses more efficient. Plus, once they decided to move to the cloud, they need to adjust their skills to suit the cloud landscape as it has become their role to match up business needs. For some companies, Information Technology (IT) is not their core business. IT is just being used as a supplement for their business. Therefore, they don't really need to have an IT expert. The absence of IT expert is one of the reasons why companies and organization hesitates to move to the cloud because there is no one to tell them which cloud services best suits them.

"they tend to fear lot of maybe enclosing their control or IT environment, maybe their budget will be cut, cut shorter or maybe in the future they will lose their job," (Interviewee 1).

According to the cloud providers, the high cost of bandwidth is one the challenges faced by cloud service providers. The cost of bandwidth in Malaysia are considerably high compared to other countries such as Vietnam, Mexico and Turkey. Even if the cloud providers want to upgrade their server from 10MB to 20MB, the cost will turn out very high.

"In Malaysia surprisingly, cost of bandwidth still high. We have spoken this to a lot of people, because, we want to $10 \mathrm{mgb}$ to $20 \mathrm{mgb}$, the cost will become high. And I think a lot of Malaysia government they know, I mean, if you compared dollar to dollar Singapore, ours is very expensive," (Interviewee 4).

Last challenge stated by the interviewee was the issues on the lifespan of IT equipment. As a cloud provider, they have to always make sure, every IT solution they provided for their clients is up to date with the latest trends. Therefore, they need to update their IT infrastructure as they cannot use the same infrastructure that has been used for 5 years. As time goes by, newly upgrade IT infrastructures will come in like new types of server, higher processing speed or better storage system. Hence, they have to upgrade their IT Infrastructure as much as they can to make sure their services are among the best.

"We need to continue to upgrade our infrastructure. Because we cannot have the same infrastructure that have been using 5 years ago. Most of the equipment, the lifespan of our equipment, the lifespan of our equipment is within 3 to 5 years," (Interviewee 4).

The findings of this study indicated scalability, endto-end management, high level security, and customizable as the reasons people move to the cloud (refer Fig. 2).

Cloud scalability in the context of cloud computing means cloud resources can be upgraded or downgraded at any time according to their business needs. Clients would be charged only for the cloud space and recourses they used, hence, the companies can reduce their IT infrastructure cost.

"As I mentioned earlier, the beauty of cloud is that you can increase the resources as and when needed, so customers will upgrade their servers only when it's necessary," (Interviewee 1).

Other than that, cloud providers will provide an endto-end management once the companies migrate to the cloud and everything will be managed by the cloud providers. Some of the companies use IT as a supplement technology as IT is not their core business, therefore, they do not hire IT experts in their companies. With the implementation of cloud computing in their business, they do not have to hire more people to maintain their IT infrastructure or to upgrade their system. This is because everything will be managed by the cloud providers.

"Because, what we offer to them is that we offered them managing end to end, they don't really need to have an IT expertise in the house," (Interviewee 4)

High security standard provided by cloud providers is also another reason people move to the cloud. Cloud providers provide 24 hours' security monitor which is significantly more efficient than a conventional inhouse system. Plus, all the security procedures such as provisioning steps, configurations, or patch steps are being carried on time by the cloud providers. By implementing cloud computing in business process, everything will be automated. As a result, human error can be reduced. IT supports are no longer having to manually configure something on local or cloud systems.

"So, for our company side, we used for data protection by using of Germany Legislation Governing so that we make sure all the information, data, contract will be secured by using Germany Legislation Law," (Interviewee 3). 
Customization is another advantage of cloud computing. People start to move to the cloud as they find customize cloud infrastructures and services can help them to grow their business without any limit. They can move to any types of cloud without getting any concerns about their business process as cloud infrastructure specifically, private cloud is very flexible. Plus, customers can actually pick and choose which types of cloud best suits their business.

"So, if they want to move to any public cloud, we can actually merge the cloud into their environment, and also connect to our environment. So, we called as hybrid cloud, where they can actually pick and choose the best of each cloud. Customizable," (Interviewee 4).

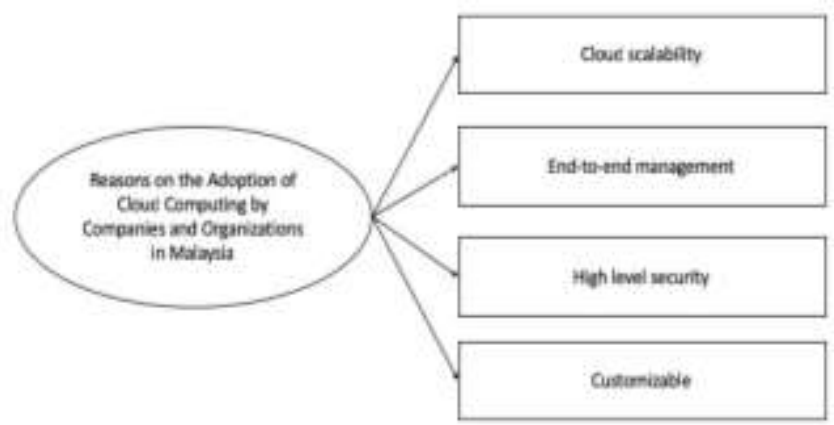

Fig. 2 Reasons on the adoption of cloud computing by companies and organizations in Malaysia.

\section{CONCLUSION}

This paper presents the finding of the challenges faced by cloud providers in providing cloud computing in Malaysia such as security concern, difficulties in learning cloud computing infrastructure, changes in IT roles, high cost of bandwidth and life span of IT equipment. This study also discovered cloud scalability, end-to-end management, high level security, and customizable as the reasons on cloud computing adoption. This study helps people to understand more about the current issues in cloud computing adoption in Malaysia from the perspectives of cloud provider and at the same time provide support to Industry 4.0.

This study uses interpretive paradigm with data collected from semi-structured interviews with three cloud providers to understand the adoption of cloud computing from cloud providers' perspectives. Therefore, this study is not intended to be generalized. In addition, further studies are needed to gain in-depth understanding of the adoption of cloud computing from the providers' perspectives.

\section{ACKNOWLEDGMENT}

The researchers in this study would like to acknowledge the Malaysian Ministry of Higher Education (MOHE) for the financial funding of this research through the Fundamental Research Grant Scheme (FRGS).

\section{REFERENCES}

[1] H. M. Sabi, F. M. E. Uzoka, K. Langmia, F. N. Njeh, "Conceptualizing a model for adoption of cloud computing in education," Int. J. Inf. Manag. Vol. 36, pp. 183-191, 2016

[2] European Commission, Communication from the Commission to the European Parliament, the Council, the European Economic and Social Committee and the Committee of the Region. Brussels, 2015.

[3] R. El-Gazzar, "Understanding the phenomenon of cloud computing adoption within organizations. Ph.D Dissertation, Faculty of Social Sciences, University of Agder, 2016.

[4] N. Islam, and Z. Islam, "An economic perspective on major cloud computing providers," Journal of Information \& Communication Technology- JICT, vol. 11, no. 1, 2017.

[5] A. Khajeh-Hosseini, D. Greenwood, and L. Sommerville, "Cloud Migration: A case study of migrating an enterprise IT System to IaaS," IEEE International Conference on Cloud Computing (CLOUD), 2010.

[6] B. Iyer, and J. C. Henderson, "Business value from clouds: learning from users," MIS Quarterly Executive, vol. 11, no. 1, pp. 51-60, 2012.

[7] S. Datta, "Go green by adopting cloud computing and virtualization," 2008, [Online]: Available from: http://www.

sandhill.com/opinion/daily_blog.php?id=59\&post=45 3

[8] S. SECTOR, O. ITU, ITU-Tfg Cloud TR, 2012.

[9] M. G. Avram, "Advantages and challenges of adopting cloud computing from an enterprise perspective," Procedia Technology, vol. 12, pp. 529-534, 2014, https://doi.org/10.1016/j.protcy.2013.12.525.

[10] S. Marston, L. Zhi, S. Bandyopadhyay, J. Zhang, and A. Ghalsasi, "Cloud computing - The business perspective," Decis. Support Syst. Vol. 51, no. 1, pp. 176-189, 2011 DOI=http://dx.doi.org/10.1016/j.dss.2010.12.006.

[11] Oracle, CLOUD: Opening up the Road to Industry 4. 0 Welcome to the new industrial revolution, 2016.

[12] P. Mell, and T. Grance, "The NIST definition of cloud computing. National Institute of Standards and Technology," vol. 53, no. 6, pp. 50, 2009.

[13] W. Kim, "Cloud Computing: Today and Tomorrow," Journal of Object Technology, Vol. 8, No. 1, 2009, pp. 65-72.

[14] Asia Cloud Computing Association (ACCA), Cloud Readiness Index. pp. 30, 2018.

[15] K. Karkonasasi, A. S. Baharudin, B. Esparham, S. A. Mousavi, "Adoption of cloud computing among enterprises in Malaysia,"Indian Journal of Science and Technology, vol. 9, no. 48, 2016.

[16] H. Hassan, and H. M. Nasir, "Determinants of cloud computing adoption at firm level: From the technological context," Journal of Engineering and Applied Sciences, vol. 12, pp. 4186-4192, 2017. 
[17]H. Hassan, "ScienceDirect organisational factors affecting cloud computing adoption in small and medium enterprises (SMEs) in service sector," Procedia Computer Science, vol. 121, pp. 976-981, 2017. https://doi.org/10.1016/j.procs.2017.11.126

[18] C. F. Ming, C. K. On, A. Rayner, T. T. Guan, and A. Patricia, "The determinant factors affecting cloud computing adoption by small and medium enterprises (SMEs) in Sabah, Malaysia," vol. 10, no.3, pp. 83-88.

[19] M. Tarmidi, S. Z. A. Rasid, \& B. Alrazi, "Cloud computing awareness and adoption among accounting practitioners in Malaysia," International Conference on Accounting Studies 2014, 164(31), 569-574, 2014.

[20]H. Sallehudin, R. C. Razak \& M. Ismail, "Factors influence cloud computing assimilation and the effect to IT operational effectiveness in public sector, " Social Sciences Postgraduate International Seminar (SSPIS), 2015.

[21]D. Schlagwein, and A. Thorogood, "Married for life? A cloud computing client - provider relationship continuance model", Proceedings of the European Conference on Information Systems (ECIS), Tel Aviv, Israel, June 9-11, 2014, ISBN 978-0-9915567-0-0h

[22] H. Hussin, M. A. Suhaimi, N. H. Mohamad Puad, A. Md Ali, "A review on cloud computing adoption from the perspectives of providers and clients," Paper presented at the 6th International Conference on Cyber and IT Service Management (CITSM), 2018, Lake Toba, Medan. 